\title{
Digestion-resistant maltodextrin effects on colonic transit time and stool weight: a randomized controlled clinical study
}

\author{
María Salud Abellán Ruiz ${ }^{1}$ María Dolores Barnuevo Espinosa ${ }^{1}$. \\ Carlos J. Contreras Fernández ${ }^{1}$ Antonio J. Luque Rubia ${ }^{1}$. \\ Francisca Sánchez Ayllón ${ }^{2}$ - Miriam Aldeguer García ${ }^{1}$ Carlos García Santamaría ${ }^{1}$. \\ Francisco Javier López Román ${ }^{1}$
}

Received: 13 March 2015 / Accepted: 14 September 2015 / Published online: 6 October 2015

(C) The Author(s) 2015. This article is published with open access at Springerlink.com

\begin{abstract}
Purpose Increased awareness of the importance of dietary fibre has led to increased interest in "functional" fibre components like digestion-resistant maltodextrin (RMD). This randomized, placebo-controlled, double-blind study assessed the effects of RMD in the colonic transit time (CTT) and defecation characteristics (frequency, stool volume and consistency).

Methods Sixty-six healthy adult volunteers (32 men) who did not have a daily defecation habit had a 7-day run-in period before the 21-day intervention period with RMD or placebo. CTT and segmental CTT (SCTT) were assessed by a single abdominal X-ray film taken at the end of both periods after radiopaque marker ingestion. Defecation characteristics and intestinal functions were also assessed, which were self-reported by patients. Intragroup comparisons were evaluated by Student's paired $t$ test, Bonferroni test and Chi-square test, while time comparisons by analysis of variance (ANOVA) and time-by-treatment interaction by repeated-measures ANOVA.

Results Fifty-seven subjects were assessed for CTT (placebo, $n=28$; RMD, $n=29$ ). In the RMD group, the total CTT, left SCTT and rectosigmoidal SCTT decreased significantly compared to baseline $(p<0.01$ each; -13.3 , $-4.7,-8.7 \mathrm{~h}, \quad$ respectively). Significant differences between groups were observed in total CTT and left SCTT.
\end{abstract}

Francisco Javier López Román

jlroman@ucam.edu

1 Cátedra de Fisiología del Ejercicio. Facultad de Ciencias de la Salud, UCAM -Universidad Católica de Murcia, Campus de los Jerónimos, n 135 Guadalupe, 30107 Murcia, Spain

2 Facultad de Enfermería, Universidad Católica San Antonio, Murcia, Spain
Significant time-by-treatment interaction was observed in the RMD group for stool volume $(p=0.014)$, increasing $56 \%$ compared to baseline $(p<0.01)$, while remained unchanged in the placebo group. Stool consistency was improved only in the RMD group $(p<0.01)$. No adverse effects related to study products were observed.

Conclusions The results show that RMD improved CTT, stool volume, stool consistency and some intestinal functions in a healthy population.

Keywords Colonic transit time $\cdot$ Resistant maltodextrin Soluble dietary fibre $\cdot$ Stool volume $\cdot$ Intestinal function

\section{Introduction}

Food processing has undoubtedly had a permanent effect on Western eating habits and led to an unparalleled reduction in dietary fibre (DF) consumption [1, 2]. The FAO and WHO recommend an adequate intake of total fibre of $38 \mathrm{~g}$ for men and $25 \mathrm{~g}$ for women [3, 4]. According to the European Food Safety Authorization (EFSA), a daily intake of $25 \mathrm{~g}$ of fibre per day is adequate for normal laxation in adults [5]. However, and following FAO/WHO recommendations [3], in the USA, a balanced diet is recommended to contain between 25 and $38 \mathrm{~g}$ of DF [6], but in reality this figure is rarely met as DF consumption is on average only $40 \%$ of the recommended dietary allowance [7]. The DF can be defined from multiple points of view, as reviewed by Fuentes-Zaragoza et al. [4]. The Codex Alimentarius Commission's Committee on Nutrition and Foods for Special Dietary Uses defined DF as "carbohydrate polymers with 10 or more monomeric units, which are not hydrolysed by the endogenous enzymes in the small intestine of humans" [8], definition that included resistant starch, 
oligosaccharides and other non-digestible carbohydrates [4]. The importance of increasing DF consumption in the general population has both health and economic benefits as it has been shown to be inversely associated with many chronic diseases such as coronary heart disease [9], certain cancers [10], diabetes [11] and obesity [12]. Furthermore, a fibre deficiency can result in a number of associated digestive and metabolic disorders such as inflammatory bowel disease, metabolic syndrome and impeded faecal transit time $[6,13,14]$. In order to combat the increasing prevalence of these disorders, "functional" fibre components, namely non-digestible carbohydrates that have beneficial physiological effects in humans, have been added to a wide variety of foods. For instance, the intake of a dairy preparation with a fibre supplement containing $20 \mathrm{~g}$ of soluble fibre improves chronic constipation [15].

In recent years, an increased awareness of the importance of DF has led to increased interest in functional DFs that are neither hydrolysed nor absorbed in the small intestine and pass into the large intestine [16]. To obtain beneficial health benefits is recommended an intake of $20 \mathrm{~g} /$ day of resistant starch (RS), a source of dietary fibre. The principal sources of RS are: whole/partly milled grains, seeds, legumes, potatoes, green bananas, high-amylose corn, bread and processed foods in which modified starches been used. However, its dietary intake can vary considerably between countries. For instance, intakes in the EU range from 3 to $6 \mathrm{~g} /$ day, in the UK resistant starch intakes are estimated to be $2.76 \mathrm{~g} /$ day, and in Sweden is estimated to be $3.2 \mathrm{~g} /$ day (reviewed in [17]). The RS food source varies depending on the RS type (reviewed in [17]). Resistant maltodextrin is obtained from corn starch through heat and enzymatic treatment. Thus, this process is comprised of a hydrolysis reaction by heat and hydrochloric acid in low humidity conditions, hydrolysis reaction with amylase, refinement and spray-dried [18, 19]. Digestion-resistant maltodextrin (RMD $[18,20,21])$ is a non-viscous soluble $\mathrm{DF}$, non-digestible carbohydrate and has been reported to have various physiological functions in humans. Intestinal regularity is typically influenced by $\mathrm{DF}$, and studies have shown that RMD increases stool frequency and volume in humans [22]. Furthermore, it has been reported that RMD is fermented by the intestinal bacterial flora, including bifidobacteria, resulting in an increase in the types and number of bacteria in the intestinal flora [20, 23-27]. Fermentation by gut bacteria leads to short-chain fatty acid (SCFA) production, mainly: acetate, propionate and butyrate. For instance, butyrate is one of the SCFA for colonic health due to its effects on promoting normal development of colonocytes. Moreover, the production of SCFA can also lower the luminal $\mathrm{pH}$, which can cause the inhibition of potentially pathogenic bacteria growth $[28,29]$. In clinical studies, RMD supplementation has been shown to be highly tolerated. Moreover, RMD has been shown to improve metabolic syndrome by reducing visceral fat and improving glucose and lipid metabolism in humans [14]. Although the effect of RMD to reduce the colonic transit time (CTT) has been confirmed in animal model studies, no human study has been reported [30].

In this context, the main aim of this study was to assess the efficacy of RMD supplementation in reducing the CTT in healthy subjects with Western diet, compared to nondigestion-resistant maltodextrin as placebo. We also evaluated the efficacy in reducing the segmental CTT (SCTT), improving defecation characteristics (frequency, stool volume and consistency) and intestinal functions.

\section{Methods}

\section{Participants}

Healthy participants aged between 18 and 30 years were recruited by advertisements at the Universidad Católica San Antonio de Murcia. Participants had a body mass index (BMI) of less than $30 \mathrm{~kg} / \mathrm{m}^{2}$ and a physical activity of less than two times per week. Likewise, they did not have a daily defecation habit, history of any digestive disease nor gastrointestinal/abdominal surgery. All participants provided informed consent and understood and fulfilled all the procedures and requirements of the study. Subjects with diabetes, pregnancy and any other conditions that the investigator regarded as unfit for the study were excluded.

\section{Design}

A randomized, placebo-controlled, double-blind, singlecentre clinical study was performed with two parallel groups: placebo (non-digestion-resistant maltodextrin) or RMD (Fibersol-2, digestion-resistant maltodextrin, Matsutani Chemical Industry Co., Ltd; [18, 20, 21]) at the Universidad Católica San Antonio de Murcia, Spain. The study protocol and the informed consent form were approved by the Independent Ethics Committee of the Universidad Católica San Antonio de Murcia. The total study duration was 28 days, including a 7-day run-in period before intervention to collect baseline data of participants. This was followed by a 21-day intervention period from day 8 to 28 where the participants consumed one of the allocated study products daily. Medications or other treatments that would result in a change in colonic transit were not permitted, as well as medication or nutritional supplement that interfered with the formulation.

Before and after the intervention period, physical examination, blood sample collection and a questionnaire survey of intestinal functions were conducted. Daily defecation 
habits, defecation frequency, stool volume and consistency, and 5-day dietary survey in each period were recorded by each subject. Medical history and adverse events (AEs) were checked at the end of each period. CTT and SCTT were assessed by radiography on days 7 and 28 .

Subject randomization was performed using a random number generator (www.random.org) that allocated the subjects in each group.

\section{Interventions}

RMD and placebo had the same appearance (in colour and size) and flavour and were provided in a 15-g sachet in powder form to be dissolved in water. Subjects were instructed to consume one sachet daily with breakfast and to maintain their normal diet throughout the study.

\section{Measurements}

\section{Colonic transit time}

To determine CTT, subjects ingested a capsule containing 24 radiopaque makers (Colognost ${ }^{\circledR}$, Iberoinversa Pharma) daily for five consecutive days at 24-h intervals. Twentyfour hours after the final marker ingestion an abdominal X-ray was performed. To calculate CTT, the time between each marker ingestion $(\Delta t)$, the number of markers observed on the X-ray $(n)$ and the number of markers ingested $(N)$ were used in the following formula [31]: CTT (h) $=(\Delta t \times n) / N$.

$\mathrm{X}$-rays were performed using a high kilovoltage and low exposure time technique to ensure that marginalized areas of the colon were included in the X-ray field. Two physicians counted the markers independently to minimize interobserver variability. Subsequently, total CTT and SCTT were calculated for each individual using the average from both counts. To segment the colon, the fifth lumbar vertebra (L5) served as central point to draw three imaginary lines: a central line from the third lumbar vertebra (L3) to L5, a right line from the L5 to the right femoral head (RFH) and a left line from the L5 to the left ilium (LI). The area above the right line (L3L5-RFH) was assigned to the right colon, the area above the left line (L3L5-LI) was assigned to the left colon, and the area below and between right and left line (IL-RFH) was assigned to the rectosigmoidal colon.

\section{Intestinal function endpoints}

Defecation frequency was self-reported. Stool consistency was determined by each subject using the Bristol Stool Chart, which has a 7-point scale from Type 1 for the hardest lumpy stools representing constipation to Type 7 for the watery stools representing diarrhoea. Ideal stool consistency covers scores from 3 to 4 . Stool volume was recorded by subjective visual estimation according to predefined comparative object. Subjects were trained to compare and to assess their stool volume converting it into a ping pong ball. Later, they reported to the UCAM roughly the number of ping pong balls they converted. Clinical variables of intestinal function were assessed according to the Rome III Criteria: straining, lumpy or hard stools, sensation of incomplete evacuation, sensation of anorectal obstruction and/or blockage, and manual maneuvers to facilitate defecation during at least $25 \%$ of defecations, as well as to have fewer than three defecations per week. A higher Rome III score correlates with higher functional constipation.

\section{Assessment dietary fibre intake}

Dietary fibre intake was assessed using a dietary survey. A five-day food record (qualitative and quantitative total intake) that was maintained by the subjects was processed using Diet source ${ }^{\circledR} 3.0$ that analysed nutritional variables including fibre consumption, energy consumption, macronutrient intake as well as any liquid ingested to ensure that there were no changes in any study phase in both groups. Subjects were advised that they should not vary their dietary habits during the study. Moreover, during marker ingestion the subjects visually recorded each meal. It was checked and verified that female subjects had the same estrogenic conditions and in no period of menstruation in the days of ingestion of radiopaque markers and measurement of colonic transit time by abdominal radiography.

\section{Safety}

The safety profile of the study products was assessed through the record of adverse events (AEs) and assessment of biochemical parameters.

Blood samples were taken before and after the intervention to asses liver function (ALT, AST) and renal function (urea and creatinine). Subjects were instructed to report any of suspicious reactions, which were evaluated by the medical staff of the Hospital Virgen de la Vega de Murcia as possible AEs.

\section{Statistical analysis}

The sample size was calculated in order to achieve the primary objective, with a confidence level of $95 \%$, beta error of $80 \%$, and estimated difference and standard deviation (SD) for the CTT of $5 \mathrm{~h}$ and 8.3, respectively [32]. The targeting number required for enrolment was 33 in each group.

Results were expressed as mean $\pm \mathrm{SD}$. The colonic transit time and the colonic segmental transit time were 
Fig. 1 Disposition of subjects for placebo (maltodextrin) and digestion-resistant maltodextrin (RMD) groups

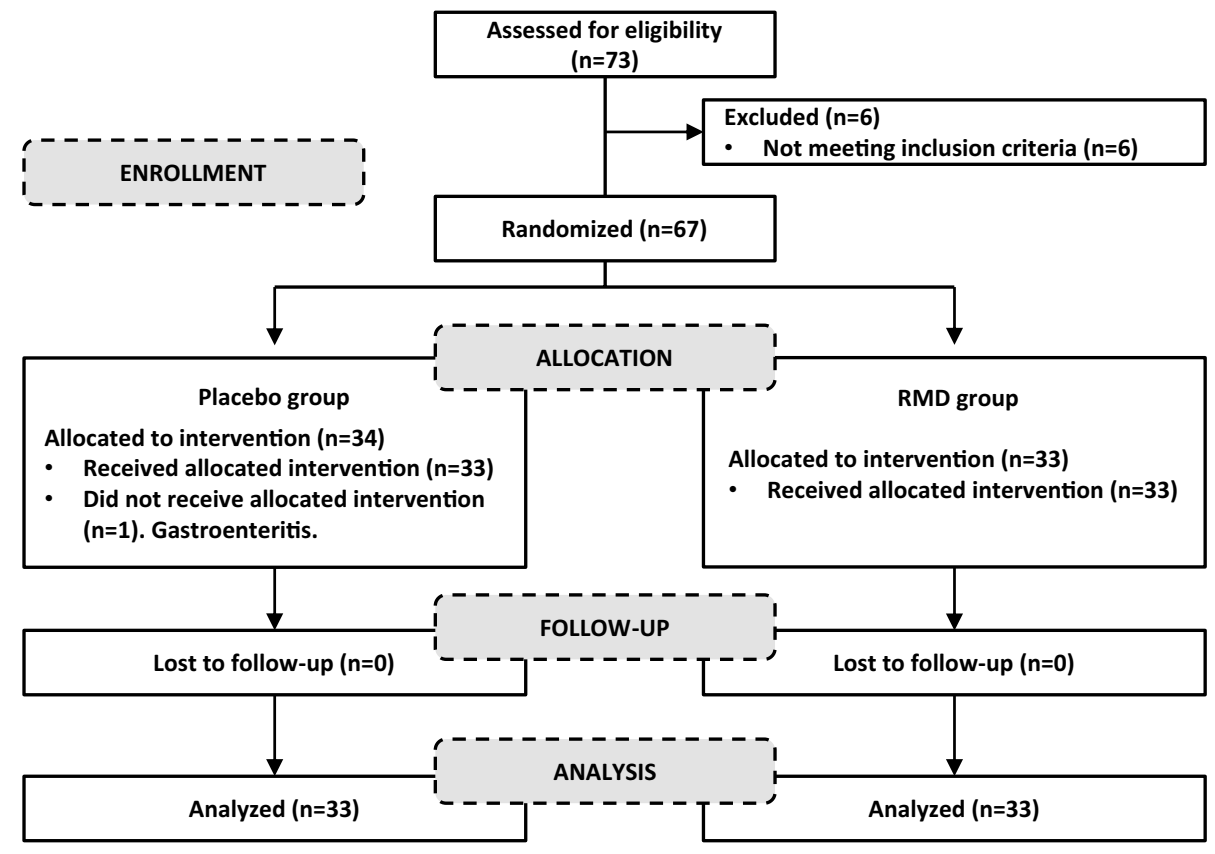

compared using ANCOVA for repeated measurements with one intrasubject factor (trial time), one intersubject factor [digestion-resistant maltodextrin (RMD) consumption, with or without consumption] and one covariable (fibre consumption). Faecal frequency, stool consistency and haematological and biochemical variables were compared using ANOVA for repeated measurements with one intrasubject factors (trial time) and one intersubject factor [digestion-resistant maltodextrin (RMD) consumption, with or without consumption]. For the comparison within a group, Dunnett' multiple comparison test was used. Clinical variables of intestinal function (Roma III criterion) were compared using the Chi-square test. All statistical analysis was performed using SPSS (version 21.0), and a $p$ value $<0.05$ was considered statistically significant.

\section{Results}

\section{Baseline data}

A total of 73 candidates were assessed for eligibility, and 67 subjects met the criteria and were randomly allocated into two groups. One subject was withdrawn during the run-in period before receiving intervention (Fig. 1). Thus, a total of 66 subjects were analysed, 33 in each study group. The demographic and other baseline characteristics of subjects in each group are outlined in Table 1. Briefly, the population was $51.5 \%$ female with the mean age of 21.3 years and the mean BMI $23.0 \mathrm{~kg} / \mathrm{m}^{2}$. The two study groups were well balanced with respect to demographics and baseline characteristics, and no significant difference
Table 1 Demographics and baseline characteristics of subjects

\begin{tabular}{llll}
\hline & Placebo $(n=33)$ & $\operatorname{RMD}(n=33)$ & Total $(n=66)$ \\
\hline Female, $n(\%)$ & $17(51.5)$ & $17(51.5)$ & $34(51.5)$ \\
Age $(\text { years })^{\mathrm{a}}$ & $21.5 \pm 3.2$ & $21.1 \pm 2.4$ & $21.3 \pm 2.8$ \\
Height $(\mathrm{m})^{\mathrm{a}}$ & $1.73 \pm 0.1$ & $1.72 \pm 0.1$ & $1.7 \pm 0.1$ \\
Weight $(\mathrm{kg})^{\mathrm{a}}$ & $70.3 \pm 14.0$ & $67.5 \pm 12.3$ & $69.0 \pm 13.1$ \\
BMI $\left(\mathrm{kg} / \mathrm{m}^{2}\right)^{\mathrm{a}}$ & $23.3 \pm 3.0$ & $22.7 \pm 3.0$ & $23.0 \pm 3.0$ \\
Smoker, $n(\%)$ & $10(30.3)$ & $8(24.2)$ & $18(27.3)$ \\
\hline
\end{tabular}

$R M D$ digestion-resistant maltodextrin, $m$ metres, $k g$ kilograms, $B M I$ body mass index, $n$ number of subjects

${ }^{\text {a }}$ Values expressed as mean \pm SD (standard deviation)

was found in any of the variables between groups. The mean daily fibre intake was $10.0 \pm 4.6 \mathrm{~g}$ in the RMD group and $11.5 \pm 4.6 \mathrm{~g}$ in the placebo group. Overall, no significant differences in the diet were observed between groups.

\section{Colonic transit time}

Although 66 subjects completed the study, 9 subjects (5 in placebo and 4 in RMD groups) failed to complete CTT determination due to non-compliance. Consequently, data from 57 subjects were used to measure CTT and SCTT.

The total CTT, left SCTT and rectosigmoidal SCTT were significantly decreased in the RMD group after intervention compared to baseline $(p<0.004, p<0.008$ and $p<0.006$, respectively), while no decrease was found in the placebo group. There are significant differences observed between groups regarding the total CTT and left SCTT ( $p<0.028$ and $p<0.001$, respectively; Table 2). Placebo 
Table 2 Change in total, right, left and rectosigmoidal colonic transit time for each group after 3 -week intervention

\begin{tabular}{llllc}
\hline Colonic transit time (h) & Treatment & Baseline & Week 3 & \multicolumn{1}{c}{$\Delta$} \\
\hline Total colon & RMD & $53.0 \pm 23.9$ & $39.7 \pm 22.3^{* *}$ & $-13.3 \pm 21.6^{\#}$ \\
& Placebo & $48.4 \pm 24.1$ & $48.0 \pm 25.0$ & $-0.4 \pm 21.4$ \\
Right colon & RMD & $12.3 \pm 8.0$ & $12.3 \pm 8.7$ & $0.1 \pm 9.6$ \\
& Placebo & $12.6 \pm 12.8$ & $12.4 \pm 9.4$ & $-0.2 \pm 10.7$ \\
Left colon & RMD & $14.9 \pm 9.9$ & $10.2 \pm 8.6^{* *}$ & $-4.7 \pm 8.8^{\# \#}$ \\
\multirow{2}{*}{ Rectosigmoidal colon } & Placebo & $9.4 \pm 9.1$ & $12.1 \pm 9.5^{*}$ & $2.7 \pm 6.5$ \\
& RMD & $25.9 \pm 18.1$ & $17.2 \pm 14.6^{* *}$ & $-8.7 \pm 15.4$ \\
& Placebo & $26.5 \pm 13.1$ & $23.6 \pm 16.0$ & $-2.9 \pm 18.7$ \\
\hline
\end{tabular}

Values expressed as mean $\pm \mathrm{SD}$ (standard deviation)

$\Delta$ : change from baseline to week 3

$* p<0.05 ; * * p<0.01$, intragroup significant difference (Student's paired $t$ test)

${ }^{\#} p<0.05 ;{ }^{\#} p<0.01$, intergroup significant differences (ANOVA)

\begin{tabular}{|c|c|c|c|c|c|}
\hline & Baseline & Week 1 & Week 2 & Week 3 & $p$ value $^{\dagger}$ time $\times$ treatment \\
\hline \multicolumn{6}{|c|}{ Stool volume $\left(\mathrm{cm}^{3} /\right.$ day $)$} \\
\hline $\begin{array}{l}\text { RMD } \\
(\Delta)\end{array}$ & $53.4 \pm 30.1$ & $\begin{array}{c}69.9 \pm 27.4^{*} \\
(16.6 \pm 32.9)\end{array}$ & $\begin{array}{c}70.2 \pm 27.3 * \\
(16.8 \pm 31.2)\end{array}$ & $\begin{array}{c}83.4 \pm 26.6^{*} \\
(30.0 \pm 27.4)^{\# \#}\end{array}$ & 0.014 \\
\hline $\begin{array}{l}\text { Placebo } \\
(\Delta)\end{array}$ & $56.4 \pm 20.6$ & $\begin{array}{c}59.4 \pm 25.0 \\
(3.0 \pm 21.4)\end{array}$ & $\begin{array}{c}64.3 \pm 25.1 \\
(7.9 \pm 24.8)\end{array}$ & $\begin{array}{c}65.6 \pm 23.8 \\
(9.2 \pm 20.0)\end{array}$ & \\
\hline \multicolumn{6}{|c|}{ Stool consistency (score) } \\
\hline $\begin{array}{l}\text { RMD } \\
(\Delta)\end{array}$ & $2.8 \pm 1.2$ & $\begin{array}{c}3.0 \pm 1.0 \\
(0.3 \pm 1.0)\end{array}$ & $\begin{array}{c}3.0 \pm 1.2 \\
(0.3 \pm 1.2)\end{array}$ & $\begin{array}{c}3.4 \pm 1.0^{*} \\
(0.6 \pm 0.8)\end{array}$ & n.s. \\
\hline $\begin{array}{l}\text { Placebo } \\
(\Delta)\end{array}$ & $2.8 \pm 0.8$ & $\begin{array}{c}3.2 \pm 0.8 \\
(0.4 \pm 1.0)\end{array}$ & $\begin{array}{c}3.2 \pm 0.7 \\
(0.4 \pm 0.9)\end{array}$ & $\begin{array}{c}3.2 \pm 0.5 \\
(0.4 \pm 0.8)\end{array}$ & \\
\hline
\end{tabular}

Values expressed as mean \pm SD (standard deviation

$\Delta$ : change from baseline to each time point; n.s.: no significant

$* p<0.05$, intragroup significant difference (Bonferroni)

${ }^{\dagger} p$ for time-by-treatment interaction was assessed by a repeated-measures ANOVA

\#\# $p<0.01$, intergroup significant differences (ANOVA) intervention did not yield any decrease for the total CTT and SCTT. Additionally, stratified analysis by gender did not show differences between placebo and RMD groups for CTT and SCTT (data not shown).

\section{Intestinal function endpoints}

The defecation frequency, stool volume, stool consistency and the number of Rome III positive criteria between the two groups did not differ at baseline. After the intervention period, there were significant increases in defecation frequency in both groups compared to baseline (RMD $65.8 \%$, placebo $56.1 \% ; p<0.01$ each). By contrast, the stool volume evolved differently between two groups. There were significant increases found in the RMD group at Week 1,2 , and $3(31,32,56 \% ; p<0.006$, $p<0.006, p<0.0001$, respectively) compared to baseline, while in the placebo group there were no changes found during intervention (Table 3). Furthermore, there was a significant time-by-treatment interaction observed in stool volume $(p=0.014)$. Based on the Bristol Scale Score self-recorded, a significant increase (softer and better stool consistency) was observed in the RMD group after 3 weeks $(21.4 \%, p<0.01)$ compared to baseline. No change was observed in the placebo group for the stool consistency. Regarding the total number of Rome III positive criteria, there were significant reductions in both RMD and placebo groups ( $p<0.01$ each).

Interestingly, analysis of the individual Rome III criteria showed that only after intervention with RMD a significant lower number of subjects (compared to baseline) answered positively to 3 out of 6 criteria: "straining" (from 63.6 to $33.3 \% ; p<0.025)$, "sensation of incomplete evacuation" (from 51.5 to $27.3 \% ; p<0.003$ ) in at least $25 \%$ of defecations, as well as "fewer than three defecations per week" (from 24.2 to $0.0 \% ; p<0.013$ ). 


\section{Safety}

During the study, six AEs were recorded (2 in placebo and 4 in RMD groups). None of the AEs were related to the study products nor classified as serious. These events were: ankle sprain, cervical muscle spasm, otitis, fever and diarrhoea. There were no clinically relevant changes observed in the biochemical parameters by haematological examination.

\section{Discussion}

This randomized, placebo-controlled, double-blind study demonstrated that daily consumption of $15 \mathrm{~g}$ of a RMD supplementation for 21 days significantly reduces the total CTT in healthy subjects. The $25.1 \%$ reduction in the total CTT was primarily due to the $31.5 \%$ reduction in the left CTT. This reduction is physiologically relevant since the total and segmented CTT at baseline was within the values previously reported for healthy individuals in other studies $[33,34]$. Some reports have been shown the gender differences [35], and others not [36]. There was no gender difference in this study. The lack of gender-related CTT differences can be accounted for by the young age range of the healthy participants [34]. Subject's loss in measurement of CTT variable for failure to measurement requirements did not affect the outcome since the loss was homogeneous in both groups. Additionally, the results presented herein are consistent to demonstrate that the intake of RMD provokes increased stool volume, better stool consistency and improvement in the intestinal functions. The consumption of daily RMD also demonstrated some more benefits to reduce the frequency of straining and sensation of incomplete evacuation. These results are consistent with the widely reported beneficial effects of DF intake [37, 38].

To our knowledge, there were no reports that confirmed a significant reducing effect on CTT in humans with other soluble DFs (SDFs) before the current study with RMD. For example, using either 15 or $20 \mathrm{~g} /$ day of inulin for 21 days did not influence CTT [39, 40]. Another study reported that $8 \mathrm{~g} /$ day of fructo-oligosaccharides (FOS) for 28 day failed in modifying CTT, and a meta-analysis of FOS concluded that there is no reducing effect on CTT [41, 42]. Among other studies of SDF, using $3.4 \mathrm{~g} /$ day of pectin for 28 days, $6 \mathrm{~g} /$ day of pectin for 21 days [43, 44], $15 \mathrm{~g} /$ day of guar gum for 18 days [45], $20 \mathrm{~g} /$ day of soluble corn fibre for 10 days [46], either 20 or $30 \mathrm{~g} /$ day of polydextrose for 10 days [46, 47] and $30 \mathrm{~g} /$ day of arabinogalactan for 21 days [48], no changes on CTT have been observed. One study with $8 \mathrm{~g}$ /day polydextrose in $100 \mathrm{~g}$ yogurt product reported to show a significant change to shorten CTT after 21-day administration; however, a significant change was also found in the placebo group, indicating that it was an effect due to the yoghurt product [49]. The current study suggests that even in the same category of SDF, the effect on the CTT is different. One of the reasons could be the characteristics that each SDF possesses such as fermentability by the intestinal bacteria and/or the presence or absence of increasing stool weight.

Faecal matter is transported from the ascending colon (right colon) to the descending colon (left colon) by intestinal peristalsis. The peristaltic motion is caused by gastrocolic reflex that occurs when food enters the stomach and in response to physical stimuli by the stool bulk. In addition, it has been reported that short-chain fatty acids (SCFAs) produced by the intestinal bacteria could also stimulate the peristalsis [50]. When ingested orally, about $10 \%$ of RMD is digested and absorbed as glucose in the small intestine, while remaining $90 \%$ reaches the large intestine. Some portion of RMD that reaches the colon is fermented slowly by the intestinal bacteria such as bifidobacteria, and the portion that escapes from bacterial fermentation is excreted with faeces. It has been confirmed that the intake of RMD leads fermentation by intestinal bacteria and production of SCFA in humans $[23,25]$. The ratio between the amount fermented and excreted has been reported as approximately $50-50$ although it could vary between individuals $[24,30]$. The fact that a part of RMD is excreted with the faeces leads to an increase in stool volume [51, 52]. Consequently, it is considered that the increased amount of stool bulk and the production of SCFA stimulate the intestinal peristalsis, contributing to the reduction in CTT.

The effect of RMD to reduce the CTT in humans was confirmed in the present study, and this effect could deeply associate with the characteristics of RMD. A distinctive characteristic of RMD is a slow speed of fermentation in the large intestine compared to other SDF. According to the previous report, the estimated speed of fermentation is FOS $>$ guar gum $>$ RMD [53]. Another report showed that inulin is faster than guar gum [54]. Therefore, FOS, inulin and guar gum are rapidly fermented and consumed in the first half of the colon, i.e. ascending colon on the right side, before reaching the second half of the colon. On the other hand, the slow and stable fermentation of RMD enables it to reach the second half of the colon, i.e. descending colon on the left side, meaning that it provides a source of fermentable carbohydrate to the more distal part of the large intestine. The SCFA produced by fermentation reportedly cause spontaneous contraction of colon [50]. Thus, it is considered that SCFA produced by RMD in the second half of the large intestine would induce the intestinal peristalsis, resulting in significant reductions in the left CTT and rectosigmoidal CTT. Consequently, the total CTT is shortened significantly. Likewise, there is also the possibility that the effect of RMD to increase stool bulk generates a synergistic 
effect with the effect of producing SCFA, which brought out the remarkable result observed after the RMD intake.

One limitation in this study could be self-reporting nature for defecation variables. However, it is important to note that this limitation could be more relevant in some variables than in others. For instance, the effect to increase stool weight and volume by the intake of RMD has been reported in the multiple human studies that evaluated this variable using either the measurement of stool weight excreted $[55,56]$ or the visual scoring method [51, 52]. The result by visual evaluation has been reported to have a high correlation with the result by weight measurement, suggesting that besides of being a simple method, the visual method is reliable [57]. By contrast, the defecation frequency could have unintentionally been increased by the subject in the placebo group, since they knew this study assessed intestinal functions. Thus, defecation frequency is easily the most evident effect that subjects could expect from the intervention and so feeling subconsciously the need to have more bowel movements. The aforementioned observation explains why defecation frequency in the placebo group was the only variable that displayed a significant change. The strengths of the present study included the reliable technique used to assess the primary endpoint. In order to obtain accurate CTT in humans, the study method is extremely important. Since Hinton et al. [58] introduced a method using radiopaque marker, it has become the standard to ingest radiopaque markers for CTT evaluation. The method, however, requires collection of faecal samples for several days to determine by X-ray, and its limitation has been pointed out that the determination of CTT based on the $80 \%$ recovery in the faeces could cause a margin of error. A new method was proposed to perform a single abdominal X-ray of subjects after every 24-h consecutive ingestion of radiopaque markers, providing a less demanding procedure for subjects to finish by only one visit for $\mathrm{X}$-ray test without faecal collection. Additionally, the method provides the data of not only CTT but also SCTT in the large intestine. In this study, a single X-ray method was used based on the method by Bouchoucha et al. to minimize radiation exposure and to obtain reliable data of CTT and SCTT [19]. As a result, CTT before and after the ingestion of placebo was almost the same, suggesting that the study to determine CTT was conducted accurately with good management of subjects and that the results have high reliability.

Although this is the first study for RMD to evaluate the efficacy on CTT in Western population, the supplementation of $15 \mathrm{~g} /$ day made up for a gap to fulfil $25 \mathrm{~g}$ of DF as recommended daily intake for adult in EU and other countries worldwide. Soluble RMD has physiological benefits and advantage as easy-to-use in food applications or as a supplement. Dietary supplementation of RMD has the possibility to help improving DF deficit in the countries, where people tend to consume more processed foods.

\section{Conclusions}

The results demonstrate that the supplementation of RMD has a beneficial effect in improving colonic transit time, stool volume, stool consistency and some clinical intestinal functions (for instance, the straining and sensation of incomplete evacuation), in a healthy young Western population. Furthermore, RMD supplementation has shown to have an adequate safety profile. The results open the possibility for the further research of RMD in patients suffering from gastrointestinal disorders in Western populations.

Acknowledgments The authors thank Dr. Yuka Kishimoto and Sumiko Kanahori for their help with experimental design and statistical analysis. The authors would like to thank Andrew Shala (TFS Develop) for his assistance in the manuscript preparation.

Authors contributions M.D.B. and F.J.L.-R. designed the research; M.S.A., M.D.B., C.J.C.F., A.J.L.R., F.S.A., M.A.G. and C.G.S. conducted the research; F.J.L.-R. and M.S.A. analysed data; M.S.A. and C.J.C.F. wrote the paper.

Funding/support This study was funded by Matsutani Chemical Industry Co., Ltd (Itami City, Hyogo, Japan).

\section{Compliance with ethical standards}

Conflict of interest The authors declare that they have no conflict of interest.

Open Access This article is distributed under the terms of the Creative Commons Attribution 4.0 International License (http://creativecommons.org/licenses/by/4.0/), which permits unrestricted use, distribution, and reproduction in any medium, provided you give appropriate credit to the original author(s) and the source, provide a link to the Creative Commons license, and indicate if changes were made.

\section{References}

1. Cervantes-Pahm SK, Liu Y, Evans A, Stein HH (2013) Effect of novel fiber ingredients on ileal and total tract digestibility of energy and nutrients in semi-purified diets fed to growing pigs. $\mathbf{J}$ Sci Food Agric. doi:10.1002/jsfa.6405

2. Fuentes-Zaragoza E, Sánchez-Zapata E, Sendra E et al (2011) Resistant starch as prebiotic: a review. Starch 63:406-415. doi:10.1002/star.201000099

3. WHO Diet, nutrition and the prevention of chronic diseases (2003). Report of the joint WHO/FAO expert consultation. In: WHO. http://www.who.int/dietphysicalactivity/publications/trs916/download/en/. Accessed 4 Aug 2015

4. Fuentes-Zaragoza E, Riquelme-Navarrete MJ, Sánchez-Zapata E, Pérez-Álvarez JA (2010) Resistant starch as functional ingredient: a review. Food Res Int 43:931-942. doi:10.1016/j. foodres.2010.02.004 
5. EFSA Panel on Dietetic Products, Nutrition and Allergies (NDA) (2010) Scientific opinion on dietary reference values for carbohydrates and dietary fibre. EFSA J 8(3):1462. doi:10.2903/j. efsa.2010.1462; www.efsa.europa.eu/efsajournal

6. Slavin JL (2008) Position of the American Dietetic Association: health implications of dietary fiber. J Am Diet Assoc 108:1716-1731

7. U.S. Department of Agriculture, U.S. Department of Health and Human Services Dietary Guidelines for Americans 2010. In: www.dietaryguidelines.gov. http://health.gov/dietaryguidelines/ dga2010/dietaryguidelines2010.pdf. Accessed 13 Nov 2013

8. Mermelstein NH (2009) Laboratory: analyzing for resistant starch. Food Technol Chic 63:80-84

9. Streppel MT, Ocké MC, Boshuizen HC et al (2008) Dietary fiber intake in relation to coronary heart disease and all-cause mortality over 40 y: the Zutphen Study. Am J Clin Nutr 88:1119-1125

10. Lattimer JM, Haub MD (2010) Effects of dietary fiber and its components on metabolic health. Nutrients 2:1266-1289. doi:10.3390/nu2121266

11. Meyer KA, Kushi LH, Jacobs DR Jr et al (2000) Carbohydrates, dietary fiber, and incident type 2 diabetes in older women. Am J Clin Nutr 71:921-930

12. Tucker LA, Thomas KS (2009) Increasing total fiber intake reduces risk of weight and fat gains in women. J Nutr 139:576581. doi:10.3945/jn.108.096685

13. Marlett JA, McBurney MI, Slavin JL, Association American Dietetic (2002) Position of the American Dietetic Association: health implications of dietary fiber. J Am Diet Assoc 102:993-1000

14. Hashizume C, Kishimoto Y, Kanahori S et al (2012) Improvement effect of resistant maltodextrin in humans with metabolic syndrome by continuous administration. J Nutr Sci Vitaminol (Tokyo) 58:423-430

15. López Román J, Martínez Gonzálvez AB, Luque A et al (2008) Efecto de la ingesta de un preparado lácteo con fibra dietética sobre el estreñimiento crónico primario idiopático. Nutr Hosp 23:12-19

16. Jones JM (2014) CODEX-aligned dietary fiber definitions help to bridge the "fiber gap". Nutr J 13:34

17. Sajilata Mg, Singhal RS, Kulkarni PR (2006) Resistant starch-a review. Compr Rev Food Sci Food Saf 5:1-17. doi:10.1111/j.1541-4337.2006.tb00076.x

18. Okuma K, Matsuda I (2003) Production of indigestible dextrin from pyrodextrin. J Appl Glycosci 50:389-394. doi:10.5458/ jag.50.389

19. U.S. Patent 5,620,873 (1997): process for preparing dextrin containing food fiber

20. Okuma K, Matsuda I, Katta Y, Hanno Y (1990) Pyrolysis of starch and its digestibility by enzymes - characterization of indigestible dextrin. Denpun Kagaku J Jpn Soc Starch Sci 37:107-114

21. Okuma K, Matsuda I (2002) Indigestible fractions of starch hydrolysates and their determination method. J Appl Glycosci Jpn 49(4):479-485

22. Baer DJ, Stote KS, Henderson T et al (2014) The metabolizable energy of dietary resistant maltodextrin is variable and alters fecal microbiota composition in adult men. J Nutr 144:10231029. doi:10.3945/jn. 113.185298

23. Miyazato S, Nakagawa C, Kishimoto Y et al (2010) Promotive effects of resistant maltodextrin on apparent absorption of calcium, magnesium, iron and zinc in rats. Eur J Nutr 49:165-171. doi:10.1007/s00394-009-0062-6

24. Goda T, Kajiya Y, Suruga K et al (2006) Availability, fermentability, and energy value of resistant maltodextrin: modeling of short-term indirect calorimetric measurements in healthy adults. Am J Clin Nutr 83:1321-1330
25. Fastinger ND, Karr-Lilienthal LK, Spears JK et al (2008) A novel resistant maltodextrin alters gastrointestinal tolerance factors, fecal characteristics, and fecal microbiota in healthy adult humans. J Am Coll Nutr 27:356-366

26. Ukhanova M, Culpepper T, Baer D et al (2012) Gut microbiota correlates with energy gain from dietary fibre and appears to be associated with acute and chronic intestinal diseases. Clin Microbiol Infect 18:62-66. doi:10.1111/j.1469-0691.2012.03859.x

27. Oku T, Nakamura S (2014) Evaluation of the relative available energy of several dietary fiber preparations using breath hydrogen evolution in healthy humans. J Nutr Sci Vitaminol (Tokyo) 60:246-254

28. Klosterbuer AS, Hullar MAJ, Li F et al (2013) Gastrointestinal effects of resistant starch, soluble maize fibre and pullulan in healthy adults. Br J Nutr 110:1068-1074. doi:10.1017/ S0007114513000019

29. Topping DL, Clifton PM (2001) Short-chain fatty acids and human colonic function: roles of resistant starch and nonstarch polysaccharides. Physiol Rev 81:1031-1064

30. Wakabayashi S, Satouchi M, Ueda Y, Ohkuma K (1992) Acute toxicity and mutagenicity studies of indigestible dextrin, and its effect on bowel movement of the rat. J Food Hyg Soc Jpn 33(6):557-562

31. Bouchoucha M, Devroede G, Arhan P et al (1992) What is the meaning of colorectal transit time measurement? Dis Colon Rectum 35:773-782

32. Pomerri F, Zuliani M, Mazza C et al (2001) Defecographic measurements of rectal intussusception and prolapse in patients and in asymptomatic subjects. AJR Am J Roentgenol 176:641645. doi:10.2214/ajr.176.3.1760641

33. Arhan P, Devroede G, Jehannin B et al (1981) Segmental colonic transit time. Dis Colon Rectum 24:625-629

34. Southwell BR, Clarke MCC, Sutcliffe J, Hutson JM (2009) Colonic transit studies: normal values for adults and children with comparison of radiological and scintigraphic methods. Pediatr Surg Int 25:559-572. doi:10.1007/s00383-009-2387-x

35. Lampe JW, Fredstrom SB, Slavin JL, Potter JD (1993) Sex differences in colonic function: a randomised trial. Gut 34:531-536

36. Jung H-K, Kim D-Y, Moon I-H (2003) Effects of gender and menstrual cycle on colonic transit time in healthy subjects. Korean J Int Med 18:181-186

37. Suares NC, Ford AC (2011) Systematic review: the effects of fibre in the management of chronic idiopathic constipation: systematic review: effect of fibre in constipation. Aliment Pharmacol Ther 33:895-901. doi:10.1111/j.1365-2036.2011.04602.x

38. Elia M, Engfer MB, Green CJ, Silk DBA (2007) Systematic review and meta-analysis: the clinical and physiological effects of fibre-containing enteral formulae. Aliment Pharmacol Ther 27:120-145. doi:10.1111/j.1365-2036.2007.03544.x

39. Slavin J, Feirtag J (2011) Chicory inulin does not increase stool weight or speed up intestinal transit time in healthy male subjects. Food Funct 2:72. doi:10.1039/c0fo00101e

40. Van Dokkum W, Wezendonk B, Srikumar TS, van den Heuvel EG (1999) Effect of nondigestible oligosaccharides on largebowel functions, blood lipid concentrations and glucose absorption in young healthy male subjects. Eur J Clin Nutr 53:1-7

41. Bouhnik Y, Achour L, Paineau D et al (2007) Four-week short chain fructo-oligosaccharides ingestion leads to increasing fecal bifidobacteria and cholesterol excretion in healthy elderly volunteers. Nutr J 6:42. doi:10.1186/1475-2891-6-42

42. Costa GT, Guimarães SB, Sampaio HAdeC (2012) Fructo-oligosaccharide effects on blood glucose: an overview. Acta Cir Bras 27:279-282. doi:10.1590/S0102-86502012000300013

43. Spiller GA, Chernoff MC, Hill RA et al (1980) Effect of purified cellulose, pectin, and a low-residue diet on fecal volatile fatty 
acids, transit time, and fecal weight in humans. Am J Clin Nutr 33:754-759

44. Hillman L, Peters S, Fisher A, Pomare EW (1983) Differing effects of pectin, cellulose and lignin on stool $\mathrm{pH}$, transit time and weight. Br J Nutr 50:189-195

45. Lampe JW, Effertz ME, Larson JL, Slavin JL (1992) Gastrointestinal effects of modified guar gum and soy polysaccharide as part of an enteral formula diet. JPEN J Parenter Enteral Nutr $16: 538-544$

46. Timm DA, Thomas W, Boileau TW et al (2013) Polydextrose and soluble corn fiber increase five-day fecal wet weight in healthy men and women. J Nutr 143:473-478. doi:10.3945/ jn. 112.170118

47. Tomlin J, Read NW (1988) A comparative study of the effects on colon function caused by feeding ispaghula husk and polydextrose. Aliment Pharmacol Ther 2:513-519

48. Robinson RR, Feirtag J, Slavin JL (2001) Effects of dietary arabinogalactan on gastrointestinal and blood parameters in healthy human subjects. J Am Coll Nutr 20:279-285

49. Hengst C, Ptok S, Roessler A et al (2009) Effects of polydextrose supplementation on different faecal parameters in healthy volunteers. Int J Food Sci Nutr 60:96-105. doi:10.1080/09637480802526760

50. Yajima T (1985) Contractile effect of short-chain fatty acids on the isolated colon of the rat. J Physiol 368:667-678

51. Umekawa T, Fujii K, Matuoka T (1999) Effect of drinks supplemented with indigestible-dextrin on fecal amount. J Nutr Food $2: 52-57$
52. Yamamoto Y, Nishida T, Sone Y (2000) The effect of ingestion of beverage supplemented with indigestible dextrin on human defecation. J Nutr Food 3:29-36

53. Flickinger EA, Wolf BW, Garleb KA et al (2000) Glucose-based oligosaccharides exhibit different in vitro fermentation patterns and affect in vivo apparent nutrient digestibility and microbial populations in dogs. J Nutr 130:1267-1273

54. Souza da Silva C, Bolhuis JE, Gerrits WJJ et al (2013) Effects of dietary fibers with different fermentation characteristics on feeding motivation in adult female pigs. Physiol Behav 110 111:148-157. doi:10.1016/j.physbeh.2013.01.006

55. Kishimoto Y, Yoshikawa Y, Miyazato S et al (2009) Effect of resistant maltodextrin on digestion and absorption of lipids. J Health Sci 55:838-844. doi:10.1248/jhs.55.838

56. Satouchi M, Wakabayashi S, Ohkuma K et al (1993) Effects of indigestible dextrin on bowel movements. Jpn J Nutr 51(1):31-37

57. Mailly HL-J, Blaszkiewicz I (2015) EFSA guidance on health claims on gut and immune function. Lexology. http://www. lexology.com/library/detail.aspx?g=7fddc59a-da51-442b-acaf286405d23504. Accessed 4 Aug 2015

58. Hinton JM, Lennard-Jones JE, Young AC (1969) A new method for studying gut transit times using radioopaque markers. Gut 10:842-847 